\title{
Restoring More Than Teeth: Dental and Oral Biomarkers of Brain Injury in Domestic Violence
}

Authors:

1. Timothy W Ellis Jr., MS

Midwestern University College of Dental Medicine Arizona, Glendale AZ, 85308

2. Sheri Brownstein, DMD

Director of Preclinical Faculty

Midwestern University College of Dental Medicine Arizona, Glendale, AZ 85308

3. Kevin Beitchman, DDS, Beitchman Orthodontics, San Antonio, TX 78230

4. Jonathan Lifshitz, PhD, University of Arizona College of Medicine - Phoenix, Phoenix, AZ, 85004; Barrow Neurological Institute at Phoenix Children's Hospital, Phoenix, AZ, 85016; Phoenix VA Healthcare System, Phoenix, AZ, 85012

Corresponding Author:

Jonathan Lifshitz, $\mathrm{PhD}$

JLifshitz@email.arizona.edu

325 ABC-1 Building

$602827-2346$

425 North Fifth Street

Phoenix, AZ 85004

Author Disclosures: Authors have nothing to disclose with respect to the content of this

manuscript. 


\begin{abstract}
While much of the focus on brain injury has centered on athletes and military veterans, victims of domestic violence (DV) comprise an under-represented cohort. Epidemiological studies show that a majority of domestic violence cases have a history of trauma to the head or neck resulting in both TBI and oral maxillofacial damage. However, distinctive oral injuries that are sustained simultaneously with brain trauma as a result of DV have yet to be fully elucidated. If a correlation can be made between specific oral injuries and TBI, then dentition may serve as a reliable biomarker for TBI. Specific dental biomarkers of injury would improve identification, diagnosis, and prognosis of TBI regardless of patient declamation. Dentists have the opportunity and obligation to add significantly to the body of knowledge regarding the frequency, presentation, profile, and characteristics of head and neck injuries of TBI in victims of DV. In so doing, the effort will fill the knowledge gaps and clarify misinformation in the lay, clinical, and scientific communities regarding the impact of TBI in DV events. The dental field can become a leader in branding the procedures, protocols, and clinical practices in the recognition and intervention against TBI in the DV population.
\end{abstract}

Keywords: Dentistry, Physical evidence, Brain Injury, Domestic Violence, 


\section{INTRODUCTION}

Approximately 1.7 million head injuries are reported in the United States every year with millions more going unreported (Langlois 2004, Langlois 2006). Traumatic brain injury (TBI) is defined as an external physical force to the head or brain resulting in neurological impairments that were not present at birth. While much of the focus on brain injury has centered on athletes and military veterans, victims of domestic violence (DV) comprise an under-represented cohort. Although the injury mechanisms may share similarities, differences in concomitant injuries, comorbidities, healthcare access, rehabilitative services, and public awareness delineate domestic violence TBI as its own public health epidemic and intensifies the impact TBI has on society. Epidemiological studies show that a majority of domestic violence cases have a history of trauma to the head or neck resulting in both TBI and oral maxillofacial damage (Ochs 1996, Le 2001). However, distinctive oral injuries that are sustained simultaneously with brain trauma as a result of DV has yet to be fully elucidated. If a correlation can be made between specific oral injuries and TBI, then dentition may serve as a reliable biomarker for TBI.

Biomarkers are distinctive substances, structures or processes that can be measured in the body or its substances that are indicative of potential disease processes aiding in diagnosis, prognosis and prediction of relevant clinical outcomes (WHO 2001, Strimbu 2010). Dental professionals must be competent in perioral and intraoral assessment in order to appropriately recognize the oral manifestations of victims who've sustained a TBI as a result of DV. The dental professional may be the first and only person to evaluate a DV victim, thus they are in unique position due to their expertise to identify, document, treat, or refer potential victims. Patients may be reticent to share circumstances surrounding trauma and 
follow-up remains dubious possibly out of for fear of retaliation from their attacker or humiliation from peers and family (MacMilan 2009, Rhodes 2007), but specific dental biomarkers of injury would improve identification, diagnosis, and prognosis of TBI regardless of patient declamation.

Due to significant advances in proteomic techniques that are more specific and selective than traditional methods, the detection of proteins amid complex high-protein-content biofluids such as serum or plasma has improved; in this manuscript however, we propose that the oral cavity may be an under-investigated area that may provide clues to TBI associated with DV. Components of the dentition provide a distinct record that accurately identifies dietary and drug abuse habits, without the need to interview patients regarding those set behaviors. These components allow individuals to be identified anthropologically and provide clues to parafunctional behaviors. Along this rationale, we propose that dentition could serve as a possible biomarker for DV related TBI. This manuscript aims to establish a possible framework for identification of particular orofacial manifestations of TBI seen in cases associated with DV. A manuscript on this topic is entirely conjecture, as minimal evidence exists, thus this manuscript will discuss basic oral-facial anatomy, possible signs and symptoms of DV seen during an oral exam, and information gathered by patient history.

\section{Domestic Violence and Traumatic Brain Injury}

Domestic violence is violent or aggressive behavior by one individual in a relationship against. This relationship may be with a spouse, partner, parent, child, guardian, or other. 
Statistics suggest that in the United States alone, one in four women and one in seven men experience domestic violence in their lifetime (Valera and Barenbaum 2003, Flury 2010) with more than half of the women experiencing a TBI as a result of DV (Garcia-Moreno 2006). As of 2017, there are approximately 325.7 million Americans comprised of approximately 166 million women (U.S. Census Bureau 2017), thus we estimate that over 41.5 million experience some type of domestic violence over their lifetime and 20.75 million will sustain a TBI as a consequence. Of that 20.75 million, roughly 8.3 million will live with some form of long-term physiological or psychological consequence of the injury (Selassie 2003, Whiteneck 2004) Moreover, in $70 \%$ of homes where women are abused, children are also abused with at least 324,000 recorded cases beginning during pregnancy making DV during pregnancy more common than maternal diabetes, preeclampsia, and neural tube defects (CDC 2014, Bacchus $2014)$.

Domestic violence often affects more than one family member, suggesting that many children who witness abuse are concomitantly victims of abuse (Appel \& Holden 1998, Edleson 2001, Tajima 2004). Roughly 10 million American children are estimated to live in such families (Carlson 1984, Straus 1992) and of those children, approximately 50\% suffer from TBI related injuries (Becker 1978, Needleman 1986, Ewing-Cobbs 1998, Cairns 2005). In mandatory reporting states, dental professionals are included in healthcare providers required to report suspected child abuse or risk felony offense charges (Kenney 2006, AZ Rev. Stat. § 13-3620(O)) Thus, identifying and reporting cases of suspected domestic violence is a professional obligation for dentists and paraprofessionals (Kenney 2006). Informing dentists on signs and symptoms of TBI \& DV injuries involving the head and neck can be a valuable tool in removing children and 
adults from situations that can impact somatic, psychosocial, and vocational function. The enduring emotional impact and psychological symptomology of TBI, especially in DV related, creates an insidious cycle that impacts future generations and communities across the United States and likely around the globe.

Emotional collapse and physical trauma to the body are typical images of DV, with reports of frequent injuries to their head, neck, and face (Jackson 2002, Muelleman 1996). Injuries can be initiated by a direct blow to the head (i.e. being hit on the head with an object or fist, gunshot to the head), the head hitting an solid object (i.e. having one's head smashed against the wall, thrown/falling to the ground), shaking of the brain (i.e. forceful whip-lash motion, rotational injury), or a loss of oxygen to the brain (i.e. strangulation, choking, near drowning) (Jackson 2002, Muelleman 1996). Many victims suffer from a TBI unknowingly, as loss of consciousness and faulty memory interfere with autobiographical reports. As such, the underlying pathology of TBI remains hidden and unassociated with TBI until a constellation of cognitive, emotional, and somatic symptoms develop (Masel and DeWitt 2010). Further vulnerability ensues if and when another head injury occurs prior to the complete healing of a previous (unknown) TBI, which can be fatal (Jackson 2002).

Misdiagnosis or lack of awareness to a TBI may be common amongst DV victims, since delayed symptoms may mirror those of mental health issues. Although unremarkable on the outside, internal and personalized symptoms of TBI can include cognitive issues like difficulty remembering information, keeping appointments, following instruction, relating to others (social failure), impatience, difficulty maintaining good boundaries, difficulty engaging appropriately with others, difficulty learning, empathy restriction, childlike emotional reactions/behavior, 
mood swings, and impulsivity (Valera and Berenbaum 2003, Monahan and O'Leary 1999).

These symptoms can sustain repeated DV events due to perceived non-compliance by the abuser and lower self-worth by the victim. Long after the physical signs of violence heal, the neurological and psychological symptoms remain. To date, conjecture surrounds the contribution

of TBI to the cycle of domestic violence, which is being addressed head on in the current issue of this journal. To this end, the oral cavity may provide subtle, yet identifiable, clues to these events prior to long-term manifestations.

\section{DENTISTRY AS IT RELATES TO DOMESTIC VIOLENCE}

As opposed to lesions elsewhere in the oral cavity, such as dental caries and oral cancer, TBI may be more difficult to identify without radiographic images or substantial patient history. Yet, dental treatment for patients who are also victims of abuse may be complicated. In children, abuse can manifest as a patient who remains hyperalert and flinches at the sudden movements of the practitioner, lacks spontaneous smiles, or avoids eye contact (Needleman 1986 ). Women with a history of abuse report greater fear of receiving dental treatment which is further exacerbated in victims of multiple assaults (Walker 1996). The fear is likely a consequence of post-traumatic stress disorder from the assaults resulting in a conditioned response to anticipated pain and a lack of control during treatment (Berggren 1939, Davey 1989, Walker 1996, Pitman 1993). Several studies have established that patients with orofacial dysfunction as a result of trauma such as temporal mandibular disorder (TMD) suffer from significantly more psychosomatic symptoms such as emotional dysregulation, pain sensitivity, anxiety, depression, 
and a diminished ability to deal with stress (Curran 1995, Campbell 2000). These findings are in line with with other TBI research.

Physical abuse in domestic violence situations commonly manifests on the head and neck, and as many as $75 \%$ of these cases can result in intra-oral injury (Halpern, 2010), yet dentists are unlikely to screen for DV related injuries (Chiodo 1994, McDowell 1994). In a survey of dentists, screening adult patients was viewed as more appropriate for the medical practitioner, although dentists admitted to more training in oral maxillofacial injuries than physicians (Kellogg 2005, Senn 2001). National dental organizations, such as the American Dental Association (ADA), do not recommend screening for DV in a dental office, citing perceived barriers in the dental office environment, including privacy, patient fear of dental treatment, and a lack of time for the practitioner (Love 2001). However, the dental healthcare team has a unique opportunity to inquire about possible DV as patients, both adult and children alike, are often unaccompanied while receiving dental treatment. Dentists may possess an interpersonal rapport with patients from routine visits that provide an opportunity for discussion. Patients will see their dental healthcare provider every six months as part of regular preventative care, even when they have no symptoms. A major barrier in the care of patients' subject to DV is the patients' willingness to disclose the altercation for economical and psychological reasons. Dental professionals or a dental team member may be the first healthcare professional to recognize signs of abuse; the dental profession has an ethical and moral responsibility to the patient to provide assistance.

BIOMARKERS \& ORAL FACIAL ANATOMY 
Intraoral and perioral trauma result from a variety of injury mechanisms. Visual assessment, a brief physical examination, and palpation for asymmetries of the face and exposed skin could identify possible DV events. Common non-abusive head injuries tend to involve the parietal bone, occiput, frontal bone, nasal bone, mandible (chin), palms of the hands, elbows, knees, and tibias (shin). Accidental injuries usually involve boney prominences, match patient history, and are appropriate for the patient's age, activities, and profession. Abnormal or atypical assault injuries frequently occur in the ears, eyes, and intra-oral soft tissue. Facial and lip trauma from the use of gags applied to the mouth may result in lichenification or scarring at the commissures of the lips (Kellogg 2005). Victims may be subjected to hot liquids, objects, or corrosives that are forced into the mouth resulting in burns, ulcerations, and scars on the posterior portion of the hard palate or buccal mucosa. Forcible feeding, in both spouses and children, commonly results in frenal tears and oral lacerations from eating utensils, baby bottles, hands, or fingers.

Oral manifestations of Gonorrhea, HPV, Chlamydia, Syphilis, and HIV may be also detected by the dental healthcare professional and when present in a minor should raise the suspicion of a possible DV situation. Unexplained erythema or petechiae on the soft and hard palate as well as the floor of the mouth may be a sign of forced oral sex. Sexual abuse may also present as an oral manifestation of a sexually transmitted disease (STD). According to the American Academy of Pediatric Dentistry (AAPD) and the American Academy of Pediatrics (APA), the presence of oral and perioral gonorrhea or syphilis in a child who is prepubescent is pathognomonic of sexual abuse, and is a plausible indicator of potential physical abuse (APA, AAPD statement). 
The stomatognathic system is comprised of the human dentition, maxilla, mandible, soft tissues of the oral cavity, and the TMJ. Each of these areas may be vulnerable in DV events and retain markers of brain injury. Obvious signs of violence that may indicate brain injury include new or healed fractures in the mandible, zygomatic-orbital complex, dentoalveolar region, and nasal bone (Goulart 2014). Tooth fractures, luxations, maxillary fracture or mandibular fracture can all be indicative of abuse and brain injury depending on patient history. Tooth discoloration, blunted roots, and pulpal necrosis may accompany such trauma or be a sign of a previous dental trauma warranting further inquiry and investigation. Other hard tissue and bony injuries of the oral cavity caused from blunt force trauma may present to a dentist or orthodontists as an unexplained malocclusion. However, hard tissue is not the only indicator of trauma, more subtle indications may be seen in the TMJ or oral soft tissue. For example, a blunt force trauma sustained across the face, can result in a deviated nasal septum, torn frenum, malocclusion, malalignment of the TMJ, or unique buccal bruising especially when an intraoral appliance is present. Malpositioned teeth as a result of trauma can cause prolonged discomfort and a chronic disease processes to manifest in tooth caries or periodontal disease. The triangle of safety, an area not regularly injured except in cases of abuse, is another area that if compromised may also correlate with a possible brain injury. Intraoral buccal or labial bruising and lingual frenal lacerations and tears in a non-ambulatory individual and intraoral injuries on nonambulatory infants is pathognomonic for abuse.

\section{OPPORTUNITIES FOR DENTISTRY TO ENGAGE}


Despite the prevalence and wide-reaching impact that domestic violence has on individuals, the community, and society as a whole, barriers still exist in the identification of abuse and provision of services. Unquestionably, this topic is difficult and easier to ignore, but doctor comfort level, cultural competency, societal norms, and overall access to care need to improve (Rodriguez 2009). We need to begin today to investigate the impact of TBI in the underrepresented, diversity cohort of DV victims. Dentistry offers underleveraged access to identify and initiate treatment of TBI in the DV population. Patients, on average, see a dentist biannually, and have a different relationship than with their medical providers (Woofolk 1999, Sohn 2005). This frequent engagement permits an opportunity for earlier diagnosis, referral, improved prognosis, and yet another safeguard for victims. Complementary manuscripts in these journal issues provide insight into treatment approaches for TBI in the context of DV.

Dentists responding in various national surveys report that they received minimal education (less than 1 hour of total instruction), if any, on DV (Love 2001). Where present, the curriculum is not tailored to dental issues and likely intermixed within lectures on public health or pediatric dentistry. There is no standardized process to teach dentists how to identify physical and behavioral indicators of domestic violence and TBI or how to report such issues. Due to the complex nature and sensitivity of the topic, it is unlikely that students will gain much experience during school. We encourage the development of specific curriculum and experiential learning approaches to enhance future dental professionals' abilities to identify, comfort, and treat injuries of possible victims. Topics for continuing education could include communication/interviewing skills, intraoral manifestations of injury, and course work on TBI/DV in general. 
Dentists have the opportunity and obligation to add significantly to the body of knowledge regarding the frequency, presentation, profile, and characteristics of head and neck injuries of TBI in victims of DV. In so doing, the effort will fill the knowledge gaps and clarify the misinformation in the lay, clinical, and scientific communities. The dental field can become a leader in branding the procedures, protocols, and clinical practices in the recognition and intervention against TBI in the DV population. If successful, an interdisciplinary approach can establish new avenues for communication between medicine and dentistry to establish national standards of care and education. The long-term goals must be to direct change towards improving quality of life for those regaining control of their own lives. Effective programs will bend and then break the cycle of abuse and DV in society. This addresses the long-term goal of moving beyond shelters towards prevention, with the aim of acting rather than reacting through an engaged and educated and technically trained workforce. 


\section{REFERENCES}

1. Langlois, J. A., Rutland-Brown, W., \& Wald, M. M. (2006). The epidemiology and impact of traumatic brain injury: a brief overview. The Journal of head trauma rehabilitation, 21(5), 375-378.

2. Langlois JA, Rutland-Brown W, Thomas KE. Traumatic Brain Injury in the United States: Emergency Department Visits, Hospitalizations, and Deaths. Atlanta: Centers for Disease Control and Prevention, National Center for Injury Prevention and Control; 2004.

3. Ochs, H. A., Neuenschwander, M. C., \& Dodson, T. B. (1996). Are head, neck and facial injuries markers of domestic violence?. The Journal of the American Dental Association, 127(6), 757-761.

4. Le, B. T., Dierks, E. J., Ueeck, B. A., Homer, L. D., \& Potter, B. F. (2001). Maxillofacial injuries associated with domestic violence. Journal of Oral and Maxillofacial Surgery, 59(11), 1277-1283.

5. WHO International Programme on Chemical Safety Biomarkers in Risk Assessment: Validity and Validation. 2001. Retrieved from http://www.inchem.org/documents/ehc/ehc/ehc222.htm.

6. Strimbu K, Tavel JA. What are Biomarkers? Current opinion in HIV and AIDS. 2010;5(6):463-466. doi:10.1097/COH.0b013e32833ed177.

7. MacMillan HL, Wathen CN, Jamieson E, et al. Screening for Intimate Partner Violence in Health Care SettingsA Randomized Trial. JAMA. 2009;302(5):493-501. doi:10.1001/jama.2009.1089

8. Rhodes KV, Frankel RM, Levinthal N, Prenoveau E, Bailey J, Levinson W. "You're Not a Victim of Domestic Violence, Are You?" Provider-Patient Communication about Domestic Violence. Annals of internal medicine. 2007;147(9):620-627.

9. Valera, E. M., \& Berenbaum, H. (2003). Brain injury in battered women. Journal of consulting and clinical psychology, 71(4), 797.

10. Flury, M., Nyberg, E., \& Riecher-Rossler, A. (2010). Domestic violence against women: definitions, epidemiology, risk factors and consequences. Swiss Med Wkly, 140(6).

11. Garcia-Moreno, C., Jansen, H. A., Ellsberg, M., Heise, L., \& Watts, C. H. (2006). Prevalence of intimate partner violence: findings from the WHO multi-country study on women's health and domestic violence. The lancet, 368(9543), 1260-1269.

12. U.S. Census Bureau (2017). Monthly Population estimates for the United States: April 1, 2010 to December 1, 2018 (NA-EST2017-01) Retrieved August 27, 2018.

13. Selassie AW, Zaloshnja E, Langlois JA, Miller T, Jones P, Steiner C. Incidence of long-term disability following traumatic brain injury hospitalization, United States, 2003. J Head Trauma Rehabil. 2008;23(2):123-131.

14. Whiteneck G, Brooks CA, Mellick D, Harrison-Felix C, Terrill MS, Noble K. Populationbased estimates of outcomes after hospitalization for traumatic brain injury in Colorado. Arch Phys Med Rehabil. 2004;85(4) Suppl. 2:S73-S81. 
15. "Intimate Partner Violence During Pregnancy, A Guide for Clinicians:" Centers for Disease Control and Prevention. Centers for Disease Control and Prevention, n.d. Web. 18 June 2014. <http://www.cdc.gov/Reproductivehealth/violence

16. Bacchus, L., Mezey, G., Bewley, S., \& Haworth, A. (2004). Prevalence of domestic violence when midwives routinely enquire in pregnancy. BJOG: An International Journal of Obstetrics and Gynaecology, 111(5), 441-445. Retrieved August 27, 2018, from http://onlinelibrary.wiley.com/doi/10.1111/j.1471-0528.2004.00108.x/full

17. Appel AE, Holden GW. The co-occurrence of spouse and physical child abuse: A review and appraisal. Journal of Family Psychology. 1998;12:578-599.

18. Edleson JL. Studying the co-occurrence of child maltreatment and domestic violence in families. In: Graham-Bermann SA, Edleson JL, editors. Domestic violence in the lives of children: The future of research, intervention, and social policy. American Psychological Association; Washington, DC: 2001. pp. 91-110.

19. Tajima EA. Correlates of the co-occurrence of wife abuse and child abuse among a representative sample. Journal of Family Violence. 2004;19:399-410.

20. Carlson BE. Children's observations of interparental violence. In: Roberts AR, editor. Battered women and their families. Springer; New York: 1984. pp. 147-167.

21. Straus MA. Children as witnesses to marital violence: A risk factor for lifelong problems among a nationally representative sample of American men and women. Ross Laboratories; Columbus, OH: 1992.

22. Ewing-Cobbs, L., Kramer, L., Prasad, M., Canales, D. N., Louis, P. T., Fletcher, J. M., ... \& Cheung, K. (1998). Neuroimaging, physical, and developmental findings after inflicted and noninflicted traumatic brain injury in young children. Pediatrics, 102(2), 300-307.

23. Cairns AM, Mok JYQ, Welbury RR. Injuries to the head, face, mouth and neck in physically abused children in a community setting. Int J Paediatr Dent 2005; 15: 310-318.

24. Becker DB, Needleman HL, Kotelchuck M. Child abuse and dentistry; orofacial trauma and its recognition by dentists. J Am Dent Assoc 1978; 97: 24-28.

25. Kenney J P. Domestic violence: a complex healthcare issue for dentistry today. Forensic Sci Int 2006; 159 Suppl 1: S121-S125.

26. AZ Rev. Stat. $§ 13-3620(0)$

27. Kenney J P. Domestic violence: a complex healthcare issue for dentistry today. Forensic Sci Int 2006; 159 Suppl 1: S121-S125.

28. Jackson, H., Philp, E., Nuttall, R. L., \& Diller, L. (2002). Traumatic brain injury: A hidden consequence for battered women. Professional Psychology: Research and Practice, 33(1), 39.

29. Muelleman, R. L., Lenaghan, P. A., \& Pakieser, R. A. (1996). Battered women: injury locations and types. Annals of emergency medicine, 28(5), 486-492.

30. Masel, B. E., \& DeWitt, D. S. (2010). Traumatic brain injury: a disease process, not an event. Journal of neurotrauma, 27(8), 1529-1540. 
31. Monahan, K., \& O'Leary, K. D. (1999). Head injury and battered women: an initial inquiry. Health \& Social Work, 24(4), 269-278.

32. Needleman, H. L. (1986). Orofacial trauma in child abuse: types, prevalence, management, and the dental profession's involvement. Pediatr Dent, 8(1), 71-80.

33. Walker EA, Milgrom PM, Weinstein P, Getz T, Richardson R. Assessing abuse and neglect and dental fear in women. J Am Dent Assoc 1996; 127(4):485-90.

34. Berggren, U., \& Meynert, G. (1984). Dental fear and avoidance: causes, symptoms, and consequences. Journal of the American Dental Association (1939), 109(2), 247-251.

35. Davey, G. C. (1989). Dental phobias and anxieties: evidence for conditioning processes in the acquisition and modulation of a learned fear. Behaviour Research and Therapy, 27(1), 51-58.

36. Pitman, R. K., Orr, S. P., \& Shalev, A. Y. (1993). Once bitten, twice shy: beyond the conditioning model of PTSD. Biological Psychiatry.

37. Curran SL, Sherman JJ, Cunningham LL, Okeson JP, Reid KI, Carlson CR. Physical and sexual abuse among orofacial pain patients: linkages with pain and psychologic distress. $J$ Orofac Pain 1995; 9(4):340-6.

38. Campbell LC, Riley JL 3rd, Kashikar-Zuck S, Gremillion H, Robinson ME. Somatic, affective, and pain characteristics of chronic TMD patients with sexual versus physical abuse histories. J Orofac Pain 2000; 14(2):112-9.

39. Chiodo GT, Tilden VP, Limandri BJ, Schmidt TA. Addressing family violence among dental patients: assessment and intervention. JADA 1994;125:69-75.

40. McDowell JD, Kassebaum DK, Fryer GE Jr. Recognizing and reporting domestic violence: a survey of dental practitioners. Spec Care Dentist 1994;14:49-53.

41. Kellogg N, American Academy of Pediatrics Committee on Child Abuse and Neglect. Oral and dental aspects of child abuse and neglect. Pediatrics 2005; 116: 15651568.

42. Senn D R, McDowell J D, Alder M E. Dentistry's role in the recognition and reporting of domestic violence, abuse, and neglect. Dent Clin North Am 2001; 45: 343-363.

43. Love, C., Gerbert, B., Caspers, N., Bronstone, A., Perry, D., \& Bird, W. (2001). Dentists' attitudes and behaviors regarding domestic violence: The need for an effective response. The Journal of the American Dental Association, 132(1), 85-93.

44. Goulart J Oral Maxillofac Res. 2014 Oct-Dec; 5(4): e4. Published online 2014 Dec 29. doi: 10.5037/jomr.2014.5404

45. Rodríguez M, Valentine JM, Son JB, Muhammad M. Intimate Partner Violence and Barriers to Mental Health Care for Ethnically Diverse Populations of Women. Trauma, violence \& abuse. 2009;10(4):358-374. doi:10.1177/1524838009339756.

46. Woolfolk, M. W., LANG, W. P., BORGNAKKE, W. S., TAYLOR, G. W., RONIS, D. L., \& NYQUIST, L. V. (1999). Determining dental checkup frequency. The Journal of the American Dental Association, 130(5), 715-723. 
47. Sohn, W., \& Ismail, A. I. (2005). Regular dental visits and dental anxiety in an adult dentate population. The Journal of the American Dental Association, 136(1), 58-66. 